\title{
Fiber Intake, Not Dietary Energy Density, Is Associated with Subsequent Change in BMI z-Score among Sub-Groups of Children
}

\author{
Sofia I. lqbal Kring Berit L. Heitmann \\ Research Unit for Dietary Studies at the Institute of Preventive Medicine, Copenhagen, Denmark
}

\section{Key Words}

Epidemiology $\cdot$ Weight gain $\cdot z$-score of BMI .

Energy density · Fiber intake

\section{Summary}

Objective: Results from short-term studies demonstrate that energy density influences energy intake, but in children and adolescents the long-term effects of energy density and obesity development are sparse. We examined the longitudinal relationship between dietary energy density, fiber intake, and body weight change over 3 years among Danish children. Methods: Multiple regression analyses were performed using anthropometric and dietary data of 398 boys and girls (8-10 years) who were enrolled in 1997/1998 and followed up in 2000/2001. Validated 24-hour recall interviews were conducted in order to collect dietary energy intake. Overweight was defined as $1.05 \mathrm{SD}$, equivalent to the 85th percentile, of age- and sex-specific BMI z-score reference values. Results: An inverse association between fiber intake and subsequent excess weight gain was observed among the normalweight boys. In overweight boys, there was a direct association with excess weight gain. A high energy intake was associated with a higher weight gain among overweight than among normal-weight boys. No significant association between dietary energy density and subsequent excess weight change was seen. The prevalence of overweight increased from 27.1 to $29.9 \%$. Mean $\Delta$-score was +0.1 and +0.4 for boys and girls, respectively. Conclusion: Dietary energy density was not associated with 3-year weight gain in boys and girls. Only energy and fiber intakes were related to weight gain, but in different ways for subgroups of normal-weight and overweight boys.

\section{Introduction}

The epidemic of overweight and obesity is no longer the exclusive domain of the adult population; greater numbers of children are now becoming overweight [1]. It is generally argued that the prevalence of overweight has increased along with the positive shift towards the consumption of energydense diets in the population [1]. In accordance, the WHO recommends reducing dietary energy density and increasing fiber intake in order to prevent and treat overweight [2]. However, so far only few studies [3-7] have examined the association between energy density and weight gain, and only a few of them have investigated children and adolescents in a prospective study design [6-8]. Short-term studies demonstrate that energy density influences energy intake [4, 9-11], but longterm effects of energy density and health outcomes are largely unexamined. For instance, dietary energy density can be reduced by increasing the fiber or water content or by reducing the sugar or fat content of the diet.

Hence, the purpose of the present study was to examine associations between dietary energy density or fiber intake and subsequent 3-year change in BMI z-score among 8- to 10-yearold boys and girls. Because metabolism may differ among those of normalweight and those who are already overweight $[12,13]$, associations were also studied among groups of normal-weight and groups of overweight children.

\section{Material and Methods}

Data from the present longitudinal study were obtained from the Danish part of the international multicenter study, the European Youth Heart Study (EYHS), in the academic year 1997/1998 and from the follow-up survey in 2000/2001.

All the participants were living in the city of Odense, which is the third largest city in Denmark.

\begin{tabular}{ll}
\hline KARGER & $\oplus$ 2008 S. Karger GmbH, Freiburg \\
Fax +497614520714 & Accessible online at: \\
Information@Karger.de & www.karger.com/ofa \\
www.karger.com &
\end{tabular}




\section{Study Population and Participants}

Inclusion criteria for and participation rate of EYHS are described in detail in a previously published article [14]. In brief, the present study population consisted of $3 \mathrm{rd}$ grade students of the EYHS study population $(\mathrm{n}=589)$. In 2001, as 6th graders, they made up the study population of adolescents for 'Fyn's Backs'. Participants with missing information on any measurement at baseline $(n=41)$ and incomplete follow-up $(n=150)$ were excluded from the analyses. In total, 398 children (181 boys and 217 girls) were eligible for analyses.

\section{Co-Variates}

\section{Anthropometric Data}

Anthropometric data were measured both at baseline and at follow-up Height $(\mathrm{cm})$ was measured to the nearest $0.1 \mathrm{~cm}$ with a stadiometer. Body weight $(\mathrm{kg})$ was measured to nearest $0.1 \mathrm{~kg}$ with a calibrated beam-scale weight. The participants wore underwear or light garments only.

\section{Dietary Information}

Two interviewers obtained information on diet from a single validated 24-hour recall interview at baseline. Prior to the study, they had training focused on interview techniques in general and, more specifically, in relation to children. During the interview, pictures of portion sizes and of the most frequently consumed food items were shown to the child for the estimation of portion sizes.

Prior to the day of the interview, all parents received a food record diary and written instructions on how to record their child's food intake. At the end of the day, the parent was encouraged to help the child describing the details of the consumed foods and liquids and the location where the meal was consumed. Thus, the dietary data used for analysis are based on both child-reported and parent-recorded data. The method of combining the 24-hour dietary recall interview with a parent's food record assisted to help secure validity of the diet information obtained for this group of relatively young children. As Danish students do not attend school on Saturday or Sunday, records are not available for Friday or Saturday. Information on food intake from the 24-hour recall interviews was entered into a Danish nutrition program (DanKost 2000, ver. 1.4), and nutrients were calculated.

The present method of assessing dietary intake is considered to be a valid method for assessing the dietary intake of children as young as 8 years old [15]. The validation study, which was based on another study sample than the present EYHS, included 12 girls and 12 boys from Odense, Denmark. The validation of the 24-hour dietary recall interviews included comparison of energy intake with energy expenditure, and the performance of total energy expenditure (TEE) was evaluated for identification of misreporting of energy intake. In total, dietary intake was assessed twice in the 14-day period of the doubly labelled water (DLW) measured TEEDLW. Valid reported energy intake was defined as EI/TEEDLW within a specified $95 \%$ confidence interval $(0.80-1.20)$. The validation showed that mean dietary energy intake was in accordance with the results from the TEEDLW for both boys and girls (not published).

\section{Energy Density}

There is no consensus about the standard calculation method for energy density. Recently, one study compared eight potential energy density calculation methods and concluded that energy density based on solid and liquid foods and beverages and their water content should be used [16]. Hence, in light of this, and also as it is the most frequently used calculation in the literature, energy density was calculated as:

$$
\text { Energy density }(\mathrm{kJ} / \mathrm{g})=\frac{\text { Energy from } \mathrm{CHO}+\text { protein }+ \text { fat }(\mathrm{kJ})}{\text { Weight of } \mathrm{CHO}+\text { protein }+ \text { fat }+ \text { fiber }+ \text { ash }+ \text { beverages }(\mathrm{g})}
$$

Dietary Fiber

Dietary fiber was analyzed as a combined group containing both soluble and insoluble fibers and was expressed in g/day.

\section{Volume}

The volume component of energy intake was defined as the water contained in the foods and beverages consumed along with and in between the meals.

\section{Fat Intake}

Dietary fat intake may influence dietary energy density and energy intake and is examined as fat energy percentage $(\mathrm{E} \%)$.

\section{Assessment of Physical Activity}

At baseline, physical activity was assessed by obtaining activity counts using the MTI accelerometer, model 7164 (Manufacturing Technology Incorporated, Fort Walton Beach, FL, USA) worn on the hip and secured by an elastic waist belt. Children wore the accelerometer for 4 consecutive days that included both weekend days. Measurements were taken during each season over a full school year to minimize the effects of seasonal variation in activity patterns.

Activity-induced energy expenditure (AEE) and TEE were predicted by using equations derived from similar measurements of physical activity on the basis of activity counts from the MTI accelerometer and sex [17]. Basal metabolic rate was predicted by subtracting AEE from TEE. Hereafter, physical activity level (PAL) was predicted as TEE over basal metabolic rate. PAL assessed by activity monitoring has been validated among the study population in a previous study [17], and the method is demonstrated to be feasible in epidemiological studies [18].

\section{Puberty}

Tanner's five-stage sexual maturation scale was used to assess the puberty stage among the school children at baseline [19]. The same trained person judged the level of puberty in Tanner's five-stage sexual maturation scale. Puberty was categorized into four stages where the lowest stage was defined as 'not started puberty' and the remaining stages indicated the level of puberty.

\section{BMI z-Score}

BMI z-score is a measurement for pediatric and adolescent under- or overweight that takes into account sex-, age- and growth-specific considerations [1]. The least mean square method (LMS) method was used to generate BMI z-scores [20].

In the present study, we applied national reference $\mathrm{z}$-scores to the study population under examination. A syntax was received with equations for calculating L, M, and S values based on large national population cohorts. The obtained equations were merged to the present data, and z-scores were generated. These z-scores for age-specific BMI were based on the difference between the observed value of the examined population and the median reference value of the reference population, standardized against the standard deviation of the reference population [20]. Hence, a $\mathrm{Z}$-score expresses excess weight gain as the amount of weight gain that is not attributable to children's normal growth.

The present analyses were adjusted for BMI z-score at baseline as a measure of initial body weight.

\section{Cut-Off Point for Overweight}

Overweight and obesity were combined, and a standard deviation in $\mathrm{z}$-scores of 1.05 above the mean equivalent to the 85 th percentile [1] was defined.

\section{Change in z-Score}

Change in z-score was defined as the change in $\mathrm{z}$-score between baseline and follow-up.

$\Delta$ z-score $=$ z-score follow-up $_{\text {- }}$-score baseline $_{\text {-s }}$ 
Table 1. Anthropometric characteristics (mean and SD) by sex and body weight level.
Table 2. Dietary information and physical activity level (PAL) (mean and SD) by sex and body weight level

\begin{tabular}{|c|c|c|c|c|c|c|}
\hline & \multicolumn{3}{|l|}{ Boys } & \multicolumn{3}{|l|}{ Girls } \\
\hline & $\begin{array}{l}\text { normal weight } \\
(\mathrm{n}=138)\end{array}$ & $\begin{array}{l}\text { overweight } \\
(\mathrm{n}=43)\end{array}$ & $\mathrm{p}$ value ${ }^{\mathrm{a}}$ & $\begin{array}{l}\text { normal weight } \\
(\mathrm{n}=152)\end{array}$ & $\begin{array}{l}\text { overweight } \\
(\mathrm{n}=65)\end{array}$ & $\mathrm{p}$ value ${ }^{\mathrm{a}}$ \\
\hline Age at baseline, years & $9.7 \pm 0.4$ & $9.5 \pm 0.4$ & $0.02 *$ & $9.6 \pm 0.4$ & $9.6 \pm 0.4$ & 0.66 \\
\hline Height at baseline, $\mathrm{cm}$ & $138.9 \pm 6.4$ & $142.4+5.6$ & 0.0012 & $137.7 \pm 6.5$ & $139.5 \pm 5.5$ & 0.06 \\
\hline Height at follow-up, cm & $160.0 \pm 8.5$ & $162.8 \pm 7.3$ & 0.05 & $159.2 \pm 7.2$ & $160.4 \pm 5.8$ & 0.24 \\
\hline Weight at baseline, $\mathrm{kg}$ & $31.5 \pm 4.2$ & $41.3 \pm 4.9$ & $<0.0001$ & $30.3 \pm 4.0$ & $39.7 \pm 5.9$ & $<0.0001$ \\
\hline Weight at follow-up, kg & $47.3 \pm 7.5$ & $61.0 \pm 8.8$ & $<0.0001$ & $46.9 \pm 6.8$ & $58.2 \pm 8.8$ & $<0.0001$ \\
\hline Change in body weight, $\mathrm{kg}$ & $15.7 \pm 4.9$ & $19.7 \pm 6.0$ & 0.0004 & $16.6 \pm 4.1$ & $18.6 \pm 6.0$ & $<0.0001$ \\
\hline BMI at baseline, $\mathrm{kg} / \mathrm{m}^{2}$ & $16.3 \pm 1.2$ & $20.3 \pm 1.6$ & $<0.0001$ & $15.9 \pm 1.3$ & $20.3 \pm 2.0$ & $<0.0001$ \\
\hline BMI at follow-up, $\mathrm{kg} / \mathrm{m}^{2}$ & $18.4 \pm 1.7$ & $23.0 \pm 2.8$ & $<0.0001$ & $18.4 \pm 1.8$ & $22.6 \pm 2.8$ & $<0.0001$ \\
\hline Z-score at baseline & $0.0 \pm 0.7$ & $1.7 \pm 0.5$ & $<0.0001$ & $-0.2 \pm 0.8$ & $1.7 \pm 0.5$ & $<0.0001$ \\
\hline Z-score at follow-up & $0.1 \pm 0.8$ & $1.7 \pm 0.7$ & $<0.0001$ & $0.2 \pm 0.8$ & $1.6 \pm 0.7$ & $<0.0001$ \\
\hline
\end{tabular}

${ }^{a} \mathrm{p}$ value for trend based on mean value in each stratum.

*Anthropometric characteristics for the boys were also significantly different after adjustment for the noted age difference.

\begin{tabular}{|c|c|c|c|c|c|c|}
\hline & \multicolumn{3}{|l|}{ Boys } & \multicolumn{3}{|l|}{ Girls } \\
\hline & $\begin{array}{l}\text { normal weight } \\
(\mathrm{n}=138)\end{array}$ & $\begin{array}{l}\text { overweight } \\
(\mathrm{n}=43)\end{array}$ & $\mathrm{p}$ value $^{\mathrm{a}}$ & $\begin{array}{l}\text { normal weight } \\
(\mathrm{n}=152)\end{array}$ & $\begin{array}{l}\text { overweight } \\
(\mathrm{n}=65)\end{array}$ & $\mathrm{p}$ value \\
\hline Energy, MJ & $9.6 \pm 2.5$ & $10.0 \pm 3.0$ & 0.21 & $9.0 \pm 2.1$ & $8.1 \pm 2.1$ & 0.01 \\
\hline Fiber, $g$ & $20.6 \pm 8.0$ & $21.2 \pm 7.7$ & 0.40 & $18.1 \pm 7.6$ & $16.4 \pm 7.1$ & 0.11 \\
\hline Energy density, kJ/g & $4.6 \pm 1.0$ & $4.4 \pm 0.9$ & 0.37 & $4.6 \pm 1.0$ & $4.3 \pm 0.8$ & 0.03 \\
\hline Volume, 1 & $1.7 \pm 0.5$ & $1.8 \pm 0.6$ & 0.16 & $1.5 \pm 0.4$ & $1.5 \pm 0.5$ & 0.60 \\
\hline Carbohydrate, E\% & $51.5 \pm 6.4$ & $51.0 \pm 7.3$ & 0.37 & $50.0 \pm 7.0$ & $50.9 \pm 6.9$ & 0.23 \\
\hline Protein, E\% & $12.2 \pm 2.5$ & $13.1 \pm 2.3$ & 0.08 & $12.5 \pm 2.7$ & $12.2 \pm 2.5$ & 0.54 \\
\hline Fat, E\% & $31.5 \pm 6.6$ & $30.6 \pm 8.2$ & 0.84 & $32.7 \pm 6.9$ & $32.0 \pm 6.8$ & 0.25 \\
\hline Energy expenditure, $\mathrm{MJ}$ & $8.0 \pm 1.9$ & $8.1 \pm 1.4$ & 0.80 & $9.3 \pm 1.5$ & $9.8 \pm 1.6$ & 0.10 \\
\hline PAL & $1.5 \pm 0.4$ & $1.4 \pm 0.3$ & 0.10 & $1.6 \pm 0.3$ & $1.6 \pm 0.2$ & 0.57 \\
\hline Reporting bias ratio* & $1.2 \pm 0.4$ & $1.3 \pm 0.4$ & 0.7 & $1.0 \pm 0.3$ & $0.9 \pm 0.3$ & 0.01 \\
\hline
\end{tabular}

${ }^{a} \mathrm{p}$ value for trend based on mean value in each stratum.

*Reporting bias ratio $=$ energy intake $/$ energy expenditure.

\section{Confounders and Effect Modifiers}

Age, puberty, physical activity, volume and fiber were considered to be potential confounders in the present study. All regression analyses were adjusted for dietary volume. In addition, fiber and fat intake and volume were adjusted for energy intake, and energy intake was adjusted for fiber intake. Boys and girls were analyzed separately to detect potential contextual and social differences in e.g. dietary patterns and physical activity habits. Stratification by overweight was done to examine whether associations were different for the normal-weight versus the overweight children.

\section{Reporting Bias}

A reporting bias ratio was calculated in order to measure the accuracy of energy intake reporting relative to energy expenditure (EI/EE) [21].

\section{Statistical Methods}

The present study used multiple linear regression models for the statistical analyses to describe associations and a standard F-test to test for interactions. Differences between groups were considered significant for $\mathrm{p}$ values $<0.05$. The analyses were carried out using SAS statistical procedures (ver. 8.0; SAS Institute Inc, Cary, NC, USA).

\section{Results}

\section{Description of Study Population}

\section{Loss to Follow-Up}

Approximately, 25\% ( $\mathrm{n}=150)$ of the $3 \mathrm{rd}$ grade students who participated in the EYHS did not participate in the follow-up survey. A drop-out analysis revealed that baseline characteristics of anthropometrics and dietary information did not differ between the participants and those who did not complete the follow-up (all $p>0.05$; data not shown).

\section{Diet and Co-Variate Characteristics}

Total energy, fiber and volume intakes were higher for boys than for girls (all $\mathrm{p} \leq 0.001)$. Energy density did not differ between the sexes. Fat intake (E\%) was higher among the girls $(\mathrm{p}=0.05)$ compared to boys. TEE was greater among girls 
Table 3. Regression analyses of dietary factors as function of change in BMI z-score $(\beta(95 \% \mathrm{CI}))$ by sex ${ }^{\mathrm{a}}$

\begin{tabular}{|c|c|c|c|c|}
\hline Characteristic & $\begin{array}{l}\text { Boys }(\mathrm{n}=181) \\
\beta(95 \% \mathrm{CI})\end{array}$ & $\begin{array}{l}\mathrm{p} \\
\text { value }\end{array}$ & $\begin{array}{l}\text { Girls }(\mathrm{n}=217) \\
\beta(95 \% \mathrm{CI})\end{array}$ & $\begin{array}{l}\mathrm{p} \\
\text { value }\end{array}$ \\
\hline \multicolumn{5}{|c|}{ Energy*, MJ/day } \\
\hline Crude & $-0.01(-0.04 ; 0.02)$ & 0.43 & $0.04(-0.0001 ; 0.07)$ & 0.05 \\
\hline Adjusted & $0.01(-0.04 ; 0.05)$ & 0.28 & $0.03(-0.02 ; 0.08)$ & 0.20 \\
\hline \multicolumn{5}{|c|}{ Energy density, kJ/g } \\
\hline Crude & $-0.04(-0.12 ; 0.05)$ & 0.41 & $0.09(0.01 ; 0.17)$ & 0.04 \\
\hline Adjusted & $-0.05(-0.16 ; 0.06)$ & 0.38 & $0.07(-0.04 ; 0.18)$ & 0.24 \\
\hline \multicolumn{5}{|l|}{ Fiber ${ }^{\dagger} ; \mathrm{g} /$ day } \\
\hline Crude & $0.53(-9.9 ; 10.9)$ & 0.92 & $1.61(-8.9 ; 12.2)$ & 0.76 \\
\hline Adjusted & $-7.11(-21.2 ; 6.9)$ & 0.32 & $2.14(-10.4 ; 14.7)$ & 0.74 \\
\hline \multicolumn{5}{|l|}{ Volume $^{\dagger}, 1 /$ day } \\
\hline Crude & $0.02(-0.13 ; 0.17)$ & 0.84 & $-0.02(-0.21 ; 0.16)$ & 0.81 \\
\hline Adjusted & $0.12(-0.19 ; 0.43)$ & 0.45 & $-0.23(-0.54 ; 0.09)$ & 0.15 \\
\hline \multicolumn{5}{|l|}{$\mathrm{Fat}^{\dagger}, \mathrm{E} \%$} \\
\hline Crude & $-0.34(-1.53 ; 0.85)$ & 0.57 & $0.59(-0.54 ; 1.73)$ & 0.30 \\
\hline Adjusted & $-0.63(-2.07 ; 0.82)$ & 0.39 & $0.07(-1.08 ; 1.25)$ & 0.72 \\
\hline
\end{tabular}

${ }^{a}$ In all the adjusted models adjustment was done for z-score, age, physical activity level, dietary volume and puberty at baseline.

*Adjusted for fiber intake.

${ }^{\dagger}$ Adjusted for energy intake. Significance level for interaction terms indicated by $\mathrm{p}$ values.

than in boys $(\mathrm{p}<0.0001)$. PAL was higher among girls than in boys $(p=0.01)$ (none of these data shown).

\section{Puberty Stage}

Approximately $45 \%$ of the girls had entered puberty at baseline and were categorized into Tanner puberty stages $2-5$.

\section{Anthropometrics, Diet and Physical Activity by Body Weight Level}

In table 1, anthropometric characteristics are given by sex and body weight level. In total, 43 boys and 65 girls were overweight or obese using the criteria of 85 th percentile (1.05 SD) as a cut-off point. This gave a baseline prevalence of $27.1 \%$ of overweight and obesity in the entire group. A comparison of BMI at baseline and follow-up showed that both sexes had increased their BMI, irrespective of whether they were normalweight or overweight at baseline (both $\mathrm{p}<0.05$; data not shown). The prevalence of overweight at follow-up had increased to $29.9 \%$, with 52 overweight boys and 67 overweight girls.

The changes in BMI z-score were different for the normalweight and the overweight children (table 1). The normalweight boys and girls had an excess weight gain of 0.1 and 0.4 BMI z-scores, respectively ( $\mathrm{p}=0.03$ and $\mathrm{p}<0.0001$, respectively; data not shown). Neither the overweight boys nor the overweight girls had a change in their excess body weight (both $\mathrm{p}$ values $>0.05$; data not shown).
In table 2, diet intakes and PALs are presented for normalweight and overweight children. Overweight girls reported a lower total energy intake ( $\mathrm{p}=0.01)$ and energy density $(\mathrm{p}=$ 0.03 ) than the normal-weight girls. Fiber intakes did not differ among the normal-weight and the overweight boys and girls. The reporting bias ratio (EI/EE) for boys and girls were almost similar, although suggestive of underreporting of energy intake in overweight girls $(\mathrm{p}=0.01)$. Therefore, we calculated the prevalence of underreporting $(\mathrm{EI} / \mathrm{EE}<0.8)$ in normalweight and overweight groups of boys and girls. Almost two thirds of the overweight girls had a reporting bias ratio below 0.8 , whereas approximately half of the normal-weight girls had a reporting bias ratio below $0.8(\mathrm{p}=0.02)$. In boys, no pattern was observed dependent on body weight level, and in both groups approximately one third had a reported bias ratio below $<0.8$ (fig. 1).

\section{Dietary Components and Subsequent Weight Change}

\section{Energy Density and Volume}

Neither dietary energy density nor dietary volume was associated with subsequent 3-year excess weight gain among boys or girls (table 3), and the association between energy density and subsequent weight change was not different after stratification by body weight level (table 4).

\section{Dietary Fiber}

Overall, fiber intake was not associated with weight changes in either gender (table 3). However, an inverse association between a high intake of dietary fiber and change in z-score was seen in the normal-weight boys, whereas a direct association was seen in the overweight boys. The analyses revealed a significant interaction between fiber intake and subsequent excess weight change for the normal-weight and overweight boys, both before and after adjustment for co-variates. An increment of $10 \mathrm{~g} /$ day of dietary fiber intake was associated with a decrease of 0.15 in z-score in the normal-weight boys. This is equivalent to an approximate weight loss of $0.9 \mathrm{~kg}$. No significant interactions were observed for girls.

\section{Energy Intake and Fat Intake}

In girls, energy intake was associated with excess weight gain before adjustment for co-variates (table 3 ). However, this association became weaker after adjustment for co-variates. There was a borderline significant interaction between energy intake and $\Delta z$-score for the normal-weight versus the overweight boys, which became significant after adjustment for covariates. The interaction showed that a high energy intake was associated with a higher weight gain among the overweight boys compared to the normal-weight boys. No significant interactions were observed for girls.

Fat intake (E\%) was not associated with subsequent 3-year excess weight gain among boys or girls (table 3 ), and the asso- 
Fig. 1. Prevalence of reporting bias ratio as a measure for the accuracy of energy intake reporting relative to energy expenditure. Cut-off value for underreporting was set to $<0.8$. p value for $\chi^{2}=0.02$ in girls. $\mathrm{p}$ value for $\chi^{2}=0.52$ in boys.

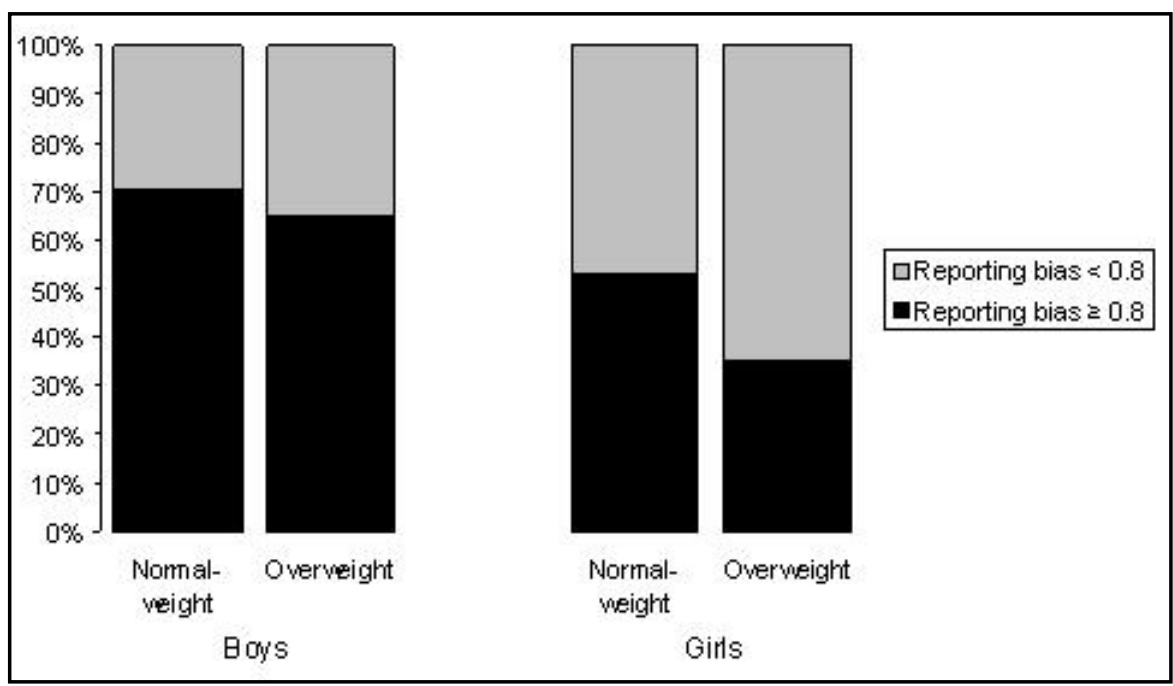

Table 4. Regression analyses of dietary factors as function of change in BMI z-score ( $\beta$ ( $95 \% \mathrm{CI})$ ) by sex and body weight level ${ }^{\mathrm{a}}$

\begin{tabular}{|c|c|c|c|c|c|c|}
\hline & \multicolumn{3}{|l|}{ Boys } & \multicolumn{3}{|l|}{ Girls } \\
\hline & $\begin{array}{l}\text { normal weight } \\
(\mathrm{n}=138)\end{array}$ & $\begin{array}{l}\text { overweight } \\
(\mathrm{n}=43)\end{array}$ & $\mathrm{p}$ value & $\begin{array}{l}\text { normal weight } \\
(\mathrm{n}=152)\end{array}$ & $\begin{array}{l}\text { overweight } \\
(\mathrm{n}=65)\end{array}$ & $\mathrm{p}$ value \\
\hline \multicolumn{7}{|c|}{ Energy*, MJ/day } \\
\hline Crude & $-0.02(-0.06 ; 0.02)$ & $0.01(-0.04 ; 0.07)$ & 0.06 & $0.01(-0.03 ; 0.06)$ & $0.03(-0.03 ; 0.09)$ & 0.43 \\
\hline Adjusted & $-0.02(-0.31 ; 0.26)$ & $0.07(-0.76 ; 0.90)$ & 0.04 & $0.02(-0.04 ; 0.08)$ & $0.09(-0.03 ; 0.21)$ & 0.66 \\
\hline \multicolumn{7}{|c|}{ Energy density, kJ/g } \\
\hline Crude & $-0.04(-0.28 ; 44.5)$ & $-0.02(-0.25 ; 0.15)$ & 0.60 & $0.02(-0.06 ; 0.02)$ & $0.21(-0.3 ; 0.31)$ & 0.93 \\
\hline Adjusted & $0.06(-0.19 ; 0.07)$ & $-0.04(-0.29 ; 0.20)$ & 0.88 & $0.04(-0.09 ; 0.16)$ & $0.23(-0.07 ; 0.53)$ & 0.51 \\
\hline \multicolumn{7}{|l|}{ Fiber $^{\dagger} ; \mathrm{g} /$ day } \\
\hline Crude & $-2.39(-14.5 ; 9.70)$ & $11.9(-8.47 ; 32.3)$ & 0.04 & $-3.72(-15.5 ; 8.05)$ & $4.66(-14.0 ; 23.3)$ & 0.95 \\
\hline Adjusted & $-10.5(-26.5 ; 5.5)$ & $14.3(-25.2 ; 53.8)$ & 0.02 & $-0.73(-15.3 ; 13.9)$ & $13.4(-15.1 ; 41.9)$ & 0.97 \\
\hline \multicolumn{7}{|c|}{ Volume $^{\dagger}, 1 /$ day } \\
\hline Crude & $0.02(-0.17 ; 0.20)$ & $0.04(-0.21 ; 0.30)$ & 0.17 & $0.01(-0.21 ; 0.23)$ & $-0.10(-0.38 ; 0.19)$ & 0.68 \\
\hline Adjusted & $0.13(-0.23 ; 0.49)$ & $0.18(-0.58 ; 0.94)$ & 0.14 & $-0.11(-0.49 ; 0.27)$ & $-0.61(-1.29 ; 0.08)$ & 0.42 \\
\hline \multicolumn{7}{|l|}{$\mathrm{Fat}^{\dagger}, \mathrm{E} \%$} \\
\hline Crude & $-0.62(-2.09 ; 0.86)$ & $0.10(-1.86 ; 2.06)$ & 0.16 & $0.74(-0.54 ; 2.01)$ & $-0.20(-2.13 ; 1.73)$ & 0.64 \\
\hline Adjusted & $-0.07(-1.83 ; 1.67)$ & $-2.50(-5.40 ; 0.40)$ & 0.61 & $0.45(-0.93 ; 1.84)$ & $-1.66(-4.58 ; 1.25)$ & 0.57 \\
\hline
\end{tabular}

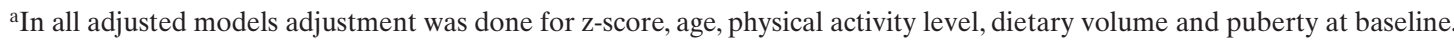

*Adjusted for fiber intake.

${ }^{\dagger}$ Adjusted for energy intake. Significance level for interaction terms indicated by $\mathrm{p}$ values.

ciation was not different after stratification by body weight level (table 4).

\section{Anthropometric Characteristics}

No differences in the anthropometric measures (age, height, weight, z-score, BMI, and change in body weight) were observed between boys and girls at baseline or follow-up (data not shown). Overall, the total change in BMI z-score was +0.1 and +0.2 for boys and girls, respectively, indicating that both sexes had a slight excess weight gain during the 3 years of follow-up.
For an easy interpretation, an estimate is given of the observed increase in z-score into an equivalent increase in body weight $(\mathrm{kg})$. The differences between the expected weight gain (16 and $15 \mathrm{~kg}$ for boys and girls, respectively, according to Danish weight-for-height and height-for-age growth charts) and the observed weight gain in $\mathrm{kg}$ gives an approximate estimation of 3-years excess weight gain of 0.7 and $2.2 \mathrm{~kg}$ for boys and girls, respectively. 


\section{Discussion}

The present study showed that energy density was not associated with subsequent weight change in either boys or girls, and fiber and energy intake was related to weight gain in different ways for subgroups of normal-weight and overweight boys. These findings are surprising given the recommendations from the WHO to reduce energy density as a measure to prevent weight gain. On the other hand, this recommendation is not supported by findings from other studies. In fact, it should be noted that evidence for this WHO recommendation is based mainly from treatment intervention studies, e.g. induction of weight loss among obese. Our results with respect to energy density are in agreement [7] and disagreement [6] with results from two studies examining the effects of energy density in children. Our findings are in contrast to the general recommendations made by the WHO to reduce energy density for the prevention and treatment of overweight. Albeit, we do acknowledge that the effects of energy density on obesity may depend on the calculation of energy density [7,16].

Other studies have shown that children may prefer high-dense food items corresponding to their increased energy and nutrient requirements during growth $[22,23]$. In the present study, a high energy-dense diet was associated with a high energy intake (data not shown), yet energy intake was not generally associated with subsequent weight change. This finding suggests that, independent of total energy intake, children may not gain excess body weight regardless of the energy density of their diet. This suggestion is also supported by some cross-sectional studies examining the association between energy density and body weight regulation in children and adolescents [24, 25].

In the present study, dietary fiber was associated with subsequent weight change among the boys. This finding is consistent with results from both intervention and prospective longitudinal studies among adult populations [26-28] and with the WHO recommendations. However, currently, fiber intake recommendations are based solely on extrapolation of data from adults [29], but studies examining the long-term effects of dietary fiber on prevention and treatment of overweight among children are absent. Albeit, it has been suggested that the effect of fiber intake on weight management in childhood and adolescence may be larger than expected [29].

In the present study, fiber and energy intakes were related to weight development among overweight boys, but not girls. The lack of significant associations among the girls may be explained by a greater underreporting of total energy intake among the overweight girls compared to normal-weight girls (table 2, fig. 1). In boys, reporting bias was not differential between normal-weight and overweight boys. Underreporting is common among adults [30,31], adolescents and children [32] and more likely to occur among overweight and obese individuals [30] and among women compared to men [30, 33]. These tendencies are apparent already during childhood in girls, and dieting is a common phenomenon even among young girls
[34]. Furthermore, a comparison of energy intake values with energy expenditure values adds evidence that overweight girls underreported their energy intake in the present study (fig. 1). Neither energy expenditure nor PAL differed between normal-weight and overweight girls.

Despite the lower energy intake and energy density among overweight girls, the absolute intake of dietary fiber and fat (E\%) did not differ significantly (table 2 ). This suggests that overweight girls, despite a general tendency to underreport, may have either overreported healthy food items such as fruits and vegetables or underreported energy-dense foods. These findings are supported by other results, suggesting specific underreporting of energy-dense foods by obese adults [30]. Overreporting of energy-dilute fiber-rich food items would contribute minimally to the total energy intake but considerably to the fiber intake. Indeed, the underreporting of total energy intake and fat intake and overreporting of dietary fiber may have contributed to the conservative findings among the girls. The findings may also be ascribed to gender differences in children's food preferences where girls have stronger taste preferences for fruit and vegetables $[35,36]$.

The present results need cautious interpretation due to a number of limitations, including a relatively small sample size. Only a single 24-hour dietary recall interview was collected for each individual and may be considered as insufficient to characterize the usual energy intake, and, hence, may explain the lack of findings in the present study. Pediatricians generally agree that the 85th and 95th percentiles can be read as ageand sex-specific BMI values approximately equivalent to BMI $\geq 25 \mathrm{~kg} / \mathrm{m}^{2}$ and $\mathrm{BMI} \geq 30 \mathrm{~kg} / \mathrm{m}^{2}$ at age 18 years [1]. However, it is still unknown at what level of pediatric obesity the detrimental effects occur, but they may occur at lower values than previously assumed $[1,37,38]$. The prevalence of overweight was also calculated as a BMI-for-age cut-off of overweight $\left(\geq 25 \mathrm{~kg} / \mathrm{m}^{2}\right)$ [39] and gave a prevalence of $14.6 \%$. It is unknown whether the true prevalence of overweight in the present study is $14.6 \%$ or $27.1 \%$ as estimated from 85 th percentile (1.05 SD), and the suitability of the different measures is not known. However, the International Obesity Task Force is aware that a lower prevalence of overweight can be estimated when using cut-off values other than BMI z-scores [1]. Some studies have validated BMI z-scores and BMI-for-age values with dual energy X-ray absorptiometry scans and observed that BMI z-score was the most precise indicator for excess body weight in children and adolescents through indirect measures [1, 40, 41].

Misclassification that would arise due to the arbitrary cut-off point when participants were categorized into normal-weight and overweight cannot be ruled out (tables 1,2,4). However, it is likely that this misclassification is directed towards the null-hypothesis and, hence, may be considered of minor importance for the present results. However, we may have overlooked true associations due to these attenuated effects. Even though adjustment was made for puberty and age, we cannot 
exclude that the observed difference in weight gain among the sexes may be attributable to residual confounding of puberty and age.

The present study shows that in 1997/1998, the prevalence of overweight and obesity, measured as $1.05 \mathrm{SD}$ (85th percentile) of BMI z-score, was $27.1 \%$ among the EYHS study population of 8-to 10-year-old boys and girls. At the follow-up in $2000 / 2001$, the prevalence had increased to $29.9 \%$. The excess weight gain was approximately equivalent to 0.7 and 2.2 body weight gain (kg) for boys and girls, respectively.

In conclusion, our results showed that dietary energy density does not seem to be associated with weight gain among children going through puberty. Dietary fiber and energy intakes were related to weight gain among subgroups of normalweight and overweight boys. However, the present results should be interpreted with caution, and more longitudinal studies are needed among children and adolescents in similar and different age groups. It seems important to examine the role of energy density and dietary fiber for obesity development separately for normal-weight and overweight children because this study suggests that the two groups may respond differently to similar diet intakes. Stratification by overweight status may also be useful because of a potential reporting bias. Further, the most precise measure for assessing excess body weight changes in childhood and adolescence still needs to be identified.

\section{Acknowledgement}

We thank statistician Peder Frederiksen for statistical advice and Dr. med. Karsten Nysom for BMI z-score reference data and helpful comments. We would also like to acknowledge the members of the European Youth Heart Study Group for valuable information and comments.

\section{Sources of Funding for Research}

The establishment of the Research Unit of Dietary Studies was financed by the FREJA (Female Researchers in Joint Action) program from the Danish Medical Research Council.

\section{Disclosure}

The authors declared no conflict of interest.

\section{References}

1 Lobstein T, Baur L, Uauy R: Obesity in children and young people: a crisis in public health. Obes Rev 2004;5(suppl 1):4-85.

2 WHO/FAO. Diet, nutrition and the prevention of chronic diseases. A report of the WHO Study Group on Diet, Nutrition and Prevention of Noncommunicable Diseases. Nutr Rev 2002;49:291-301.

3 Iqbal SI, Helge JW, Heitmann BL: Do energy density and dietary fiber influence subsequent 5-year weight changes in adult men and women? Obesity (Silver Spring) 2006;14:106-114.

4 Rolls BJ, Bell EA, Castellanos VH, Chow M, Pelkman CL, Thorwart ML: Energy density but not fat content of foods affected energy intake in lean and obese women. Am J Clin Nutr 1999;69:863-871.

5 Ello-Martin JA, Roe LS, Ledikwe JH, Beach AM, Rolls BJ: Dietary energy density in the treatment of obesity: a year-long trial comparing 2 weight-loss diets. Am J Clin Nutr 2007;85:1465-1477.

6 Johnson L, Mander AP, Jones LR, Emmett PM Jebb SA: A prospective analysis of dietary energy density at age 5 and 7 years and fatness at 9 years among UK children. Int J Obes 2007;32:586-593.

7 McCaffrey TA, Rennie KL, Kerr MA, et al: Energy density of the diet and change in body fatness from childhood to adolescence; is there a relation? Am J Clin Nutr 2008;87:1230-1237.

8 Kral TVE, Berkowitz RI, Stunkard AJ, Stallings VA, Brown DD, Faith MS: Dietary energy density increases during early childhood irrespective of familial predisposition to obesity: results from a prospective cohort study. Int J Obes 2007;31: 1061-1067.

9 Prentice AM: Manipulation of dietary fat and energy density and subsequent effects on substrate flux and food intake. Am J Clin Nutr 1998;67(3 suppl): 535S-541S
10 Stubbs RJ, Harbron CG, Murgatroyd PR, Prentice AM: Covert manipulation of dietary fat and energy density: effect on substrate flux and food intake in men eating ad libitum. Am J Clin Nutr 1995;62: 316-29.

11 Ledikwe JH, Rolls BJ, Smiciklas-Wright H, et al: Reductions in dietary energy density are associated with weight loss in overweight and obese participants in the PREMIER trial. Am J Clin Nutr 2007; 85:1212-1221.

12 Wang Y: Is obesity associated with early sexual maturation? A comparison of the association in American boys versus girls. Pediatrics 2002;110: 903-910.

13 Michaelsen KF, Jorgensen MH: Dietary fat content and energy density during infancy and childhood; the effect on energy intake and growth. Eur J Clin Nutr 1995;49:467-483.

14 Wedderkopp N, Leboeuf-Yde C, Andersen LB, Froberg K, Hansen HS: Back pain reporting pattern in a Danish population-based sample of children and adolescents. Spine 2001;26:1879-1883.

15 Lytle LA, Nichaman MZ, Obarzanek E, et al: Validation of 24-hour recalls assisted by food records in third-grade children. The CATCH Collaborative Group. J Am Diet Assoc 1993;93:1431-1436.

16 Ledikwe JH, Blanck HM, Khan LK, et al: Dietary energy density determined by eight calculation methods in a nationally representative United States population. J Nutr 2005;135:273-278.

17 Ekelund U, Sjostrom M, Yngve A, et al: Physical activity assessed by activity monitor and doubly labeled water in children. Med Sci Sports Exerc 2001;33:275-281.

18 Riddoch CJ, Bo AL, Wedderkopp N, et al: Physical activity levels and patterns of 9- and 15-yr-old European children. Med Sci Sports Exerc 2004;36: 86-92.
19 Tanner JM: Growth and maturation during adolescence. Nutr Rev 1981;39:43-55.

20 Nysom K, Molgaard C, Hutchings B, Michaelsen KF: Body mass index of 0 to 45 -y-old Danes: reference values and comparison with published European reference values. Int J Obes Relat Metab Disord 2001;25:177-184.

21 Black AE, Cole TJ: Within- and between-subject variation in energy expenditure measured by the doubly-labelled water technique: implications for validating reported dietary energy intake. Eur J Clin Nutr 2000;54:386-394.

22 Birch LL: Development of food preferences. Annu Rev Nutr 1999;19:41-62.

23 Birch LL: Children's preferences for high-fat foods. Nutr Rev 1992;50:249-255.

24 Michaelsen KF, Jorgensen MH: Dietary fat content and energy density during infancy and childhood; the effect on energy intake and growth. Eur J Clin Nutr 1995;49:467-483.

25 Gibson EL, Wardle J: Energy density predicts preferences for fruit and vegetables in 4-year-old children. Appetite 2003;41:97-98.

26 Ludwig DS, Pereira MA, Kroenke $\mathrm{CH}$, et al: Dietary fiber, weight gain, and cardiovascular disease risk factors in young adults. JAMA 1999;282: 1539-1546.

27 Stamler J, Dolecek TA: Relation of food and nutrient intakes to body mass in the special intervention and usual care groups in the Multiple Risk Factor Intervention Trial. Am J Clin Nutr 1997;65(1 suppl): 366S-373S.

28 Raben A, Jensen ND, Marckmann P, Sandstrom B, Astrup A: Spontaneous weight loss during 11 weeks' ad libitum intake of a low fat/high fiber diet in young, normal weight subjects. Int J Obes Relat Metab Disord 1995;19:916-923. 
29 Edwards CA, Parrett AM: Dietary fibre in infancy and childhood. Proc Nutr Soc 2003;62:17-23.

30 Heitmann BL, Lissner L: Dietary underreporting by obese individuals - is it specific or non-specific? BMJ 1995;311:986-989.

31 Black AE, Cole TJ: Biased over- or under-reporting is characteristic of individuals whether over time or by different assessment methods. J Am Diet Assoc 2001;101:70-80.

32 Livingstone MB, Robson PJ, Black AE, et al: An evaluation of the sensitivity and specificity of energy expenditure measured by heart rate and the Goldberg cut-off for energy intake: basal metabolic rate for identifying mis-reporting of energy intake by adults and children: a retrospective analysis. Eur J Clin Nutr 2003;57:455-463.

33 Novotny JA, Rumpler WV, Riddick H, et al: Personality characteristics as predictors of underreporting of energy intake on 24-hour dietary recall interviews. J Am Diet Assoc 2003;103: 1146-1151.
34 Samuelson G: Dietary habits and nutritional status in adolescents over Europe. An overview of current studies in the Nordic countries. Eur J Clin Nutr 2000;54(suppl 1):S21-S28

35 Cooke LJ, Wardle J: Age and gender differences in children's food preferences. Br J Nutr 2005;93: 741-746.

36 Brug J, Tak NI, te Velde SJ, Bere E, de Bourdeaudhuij I:. Taste preferences, liking and other factors related to fruit and vegetable intakes among schoolchildren: results from observational studies. Br J Nutr 2008;99(suppl 1):S7-S14.

37 Dietz WH, Bellizzi MC: Introduction: the use of body mass index to assess obesity in children. Am J Clin Nutr 1999;70:123S-125S.

38 Baker JL, Olsen LW, Sørensen TIA: Childhood body-mass index and the risk of coronary heart disease in adulthood. N Engl J Med 2007;357: 2329-2337.
39 Cole TJ, Bellizzi MC, Flegal KM, Dietz WH: Establishing a standard definition for child overweight and obesity worldwide: international survey. BMJ 2000;320:1240-1243.

40 Field AE, Laird N, Steinberg E, Fallon E, SemegaJanneh M, Yanovski JA: Which metric of relative weight best captures body fatness in children? Obes Res 2003;11:1345-1352.

41 Cole TJ, Faith MS, Pietrobelli A, Heo M: What is the best measure of adiposity change in growing children: BMI, BMI\%, BMI z-score or BMI centile? Eur J Clin Nutr 2005;59:419-425. 